\title{
Impact of Shallow and Deep Water Exercise on Health Related Physical Fitness and Physiological Variables among of Obese Adults
}

\author{
N. R. Ramkumar \\ Director, Department of Physical Education, \\ Academy of Maritime Education and Training University, Chennai, Tamil Nadu, India \\ E-Mail: ram.sportive@gmail.com
}

\begin{abstract}
Aim of the study was to find out the Impact of shallow and deep water exercise on health related physical fitness and physiological variables among of obese adults. For this purpose, forty five $(n=45)$ obese men adults residing in Kanchipuram District, Tamil Nadu, India were selected as subjects at random and they were divided randomly into two Experimental groups and one experimental group of fifteen each. Group-I underwent shallow water exercise, Group-II underwent Deep water exercise and Group-III acted as Control. The training period was limited to eight weeks and for five days per week. Among various health related physical fitness and physiological variables Flexibility and Respiratory rate only selected as dependent variables for this study. The dependent variable Flexibility was assessed by Sit \& Reach Test and Respiratory Rate was assessed by Manual Method. All the subjects were tested prior to and immediately after the experimental period on the selected dependent variables. The data obtained from the Experimental groups and control group before and after the experimental period was statistically analyzed Analysis of covariance (ANCOVA). Whenever the ' $F$ ' ratio for adjusted posttest means was found to be significant, the Scheffe's test was applied as post-hoc test to determine the paired mean differences. The level of confidence was fixed at .05 levels for all the cases. The results of the study showed Deep water exercise group was better than shallow water exercise group and control group.

Keywords: Shallow Water Exercise, Deep Water Exercise, Flexibility, Respiratory Rate
\end{abstract}

\section{INTRODUCTION}

Besides, water exercise which also called aquatic exercise program, aqua aerobics, water aerobics, shallow -water or deep -water running or walking exercise, and shallow or deep -water, aqua aerobic exercise, or similar titles are safer than land-based exercise to reduce risk of injuries and difficulty of exercise (Kantyka, J., et al., 2015).Health and sports professionals have recommended water-based exercises as an alternative to traditional dry-land exercise, leading to a significant increase in physical exercise performed in an aquatic context [Raffaelli $C$ et al., 2016].

The properties of the aquatic environment, which reduce the effect of body weight on the joints and compression forces and reduce the risk of injury or fall, combined with the resistance of the water during all movements, make it beneficial for overall body exercise and recovery from injuries [Alberton L et al., 2013., Borreani S et al., 2014].

\section{METHODOLOGY}

To attain the purpose, forty five $(\mathrm{N}=45)$ obese adult residing from Kanchipuram district, Tamil Nadu, India were selected as subjects and their age ranged from 21-30 years. The selected subjects were randomly assigned into three groups of fifteen each, namely, shallow water exercise group, deep water exercise group and control group. The training period was limited to eight weeks and for five days per week. Among various health related physical fitness and physiological variables Flexibility and Respiratory rate only selected as dependent variables for this study.

The dependent variable such as Flexibility and Resting Pulse Rate were assessed by Sit \& Reach Test and Manual Method respectively. All the subjects were tested prior to and immediately after the experimental period of eight weeks on the selected dependent variables.

\section{STATISTICAL PROCEDURE}

The data obtained from the shallow water exercise group, deep water exercise group and control group before and after the experimental period were statistically analyzed with Analysis of covariance (ANCOVA). Whenever the ' $F$ ' ratio for adjusted post test means was found to be significant, the Scheffe's test was applied as post-hoc test to determine the paired mean differences. The level of confidence was fixed at 0.05 levels for all the cases.

\section{ANALYSIS OF THE DATA}

The analysis of covariance on Flexibility and Resting Pulse Rate of the pre, post, and adjusted test scores of shallow water exercise group, deep water exercise group and Control group have been analyzed and presented in Table I.

Table I shows that the adjusted post test mean value of Flexibility and Respiratory rate for Shallow water exercise group, Deep water exercise group and Control group, are $20.68,23.26,17.86,17.14,16.40$ and 19.39 respectively. The obtained F-ratio of 218.31 and 87.64 for the adjusted post test mean is more than the table value of 3.23 for $\mathrm{df} 2$ and 41 required for significance at 0.05 level of confidence. The results of the study indicate that there are significant differences among the adjusted post test means of Shallow water exercise group, Deep water exercise group and 
Control group on the increase in Flexibility and decrease in Respiratory rate. To determine which of the paired means had a significant difference, Scheffe's test was applied as Post hoc test and the results are presented in Table II.

TAble I Analysis Of Covariance For Shallow Water EXercise Group, DeEP Water EXercise Group ANd Control GROUP ON SELECTED DEPENDENT VARIABLES

\begin{tabular}{|c|c|c|c|c|c|c|c|c|}
\hline \multirow[b]{2}{*}{$\begin{array}{l}\text { Certain } \\
\text { Variables }\end{array}$} & \multicolumn{3}{|c|}{ Adjusted Post test Means } & \multirow[b]{2}{*}{ SV } & \multirow[b]{2}{*}{ SQ } & \multirow[b]{2}{*}{ df } & \multirow[b]{2}{*}{ MS } & \multirow[b]{2}{*}{$\begin{array}{c}\text { 'F' } \\
\text { Ratio }\end{array}$} \\
\hline & $\begin{array}{c}\text { Shallow water } \\
\text { Exercise } \\
\text { Group - (I) }\end{array}$ & $\begin{array}{c}\text { Deep Water } \\
\text { Exercise } \\
\text { Group - (II) }\end{array}$ & $\begin{array}{c}\text { Control } \\
\text { Group - (III) }\end{array}$ & & & & & \\
\hline Flexibility & 20.68 & 23.26 & 17.86 & $\begin{array}{l}\mathrm{Bt} \\
\mathrm{Wi} \\
\end{array}$ & $\begin{array}{c}216.12 \\
20.29 \\
\end{array}$ & $\begin{array}{c}2 \\
41 \\
\end{array}$ & $\begin{array}{c}108.06 \\
0.49\end{array}$ & $218.31 *$ \\
\hline $\begin{array}{c}\text { Respiratory } \\
\text { Rate }\end{array}$ & 17.14 & 16.40 & 19.39 & $\begin{array}{l}\mathrm{Bt} \\
\mathrm{Wi}\end{array}$ & $\begin{array}{l}72.83 \\
17.04\end{array}$ & $\begin{array}{c}2 \\
41\end{array}$ & $\begin{array}{c}36.42 \\
0.42\end{array}$ & $87.64 *$ \\
\hline
\end{tabular}

* Significant at.05 level of confidence, (The table value required for Significance at .05 level with df 2 and 41 is 3.23)

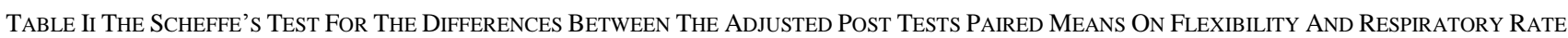

\begin{tabular}{|c|c|c|c|c|c|}
\hline \multirow[b]{2}{*}{$\begin{array}{c}\text { Certain } \\
\text { Variables }\end{array}$} & \multicolumn{3}{|c|}{ Adjusted Post test Means } & \multirow[b]{2}{*}{$\begin{array}{c}\text { Mean } \\
\text { Difference }\end{array}$} & \multirow[b]{2}{*}{$\begin{array}{l}\text { Confidence } \\
\text { Interval }\end{array}$} \\
\hline & $\begin{array}{c}\text { Shallow water } \\
\text { Exercise } \\
\text { Group - (I) }\end{array}$ & $\begin{array}{c}\text { Deep Water } \\
\text { Exercise } \\
\text { Group - (II) }\end{array}$ & $\begin{array}{c}\text { Control Group } \\
- \text { (III) }\end{array}$ & & \\
\hline \multirow{3}{*}{ Flexibility } & 20.68 & 23.26 & & $2.58 *$ & 0.65 \\
\hline & 20.68 & & 17.86 & 2.82 & 0.65 \\
\hline & & 23.26 & 17.86 & 5.40 & 0.65 \\
\hline \multirow{3}{*}{$\begin{array}{l}\text { Respiratory } \\
\text { Rate }\end{array}$} & 17.14 & 16.40 & & 0.74 & 0.60 \\
\hline & 17.14 & & 19.39 & 2.25 & 0.60 \\
\hline & & 16.40 & 19.39 & 2.99 & 0.60 \\
\hline
\end{tabular}

Table II shows that the adjusted post test mean difference for Flexibility on shallow water exercise group and deep water exercise group, shallow water exercise group and control group, deep water exercise group and control group are 2.58, 2.82 and 5.40 respectively, these values are greater than the confidence interval value 0.60 , which shows significant differences at 0.05 level of confidence. It may be concluded from the results of the study that there is a significant difference in flexibility between the adjusted post test means of shallow water exercise group and deep water exercise group, shallow water exercise group and control group, deep water exercise group and control group. However, the improvement in Flexibility was significantly increased for deep water exercise group than shallow water exercise group and control group.

Further the table III shows that the adjusted post test mean difference for respiratory rate on shallow water exercise group and deep water exercise group, shallow water exercise group and control group, deep water exercise group and control group are $0.74,2.25$ and 2.99 respectively, these values are greater than the confidence interval value 0.60 , which shows significant differences at 0.05 level of confidence.

It may be concluded from the results of the study that there is a significant difference in respiratory rate between the adjusted post test means of shallow water exercise group and deep water exercise group, shallow water exercise group and control group, deep water exercise group and control group. However, the improvement in respiratory rate was significantly increased for deep water exercise group than shallow water exercise group and control group. It may be concluded that the deep water exercise group is better than the shallow water exercise group and control in improving and decreasing flexibility and respiratory rate. The adjusted post test means values of experimental groups and control group on flexibility and respiratory rate are graphically represented in the Fig. 1 and Fig. 2.

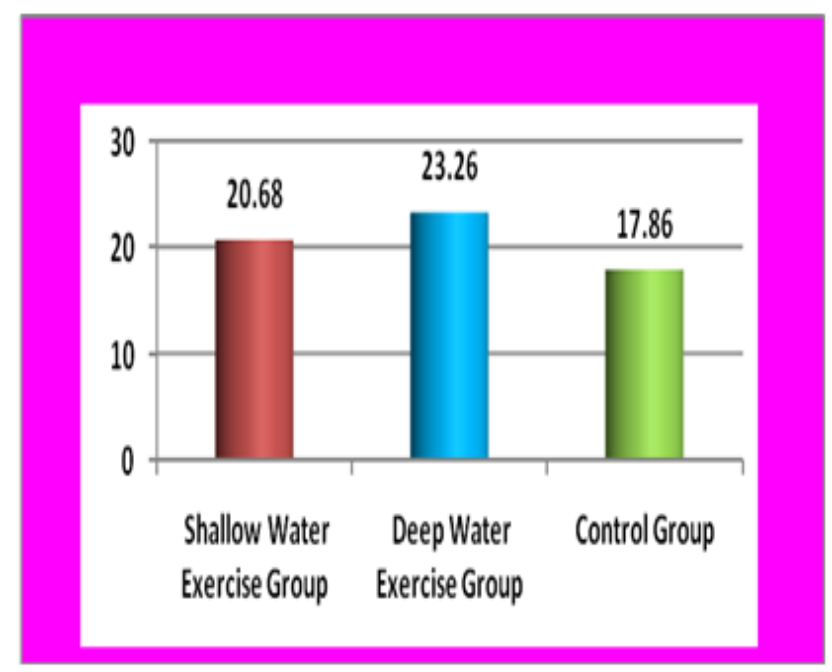

Fig. 1 Bar Diagram on Ordered Adjusted Means of Flexibility 


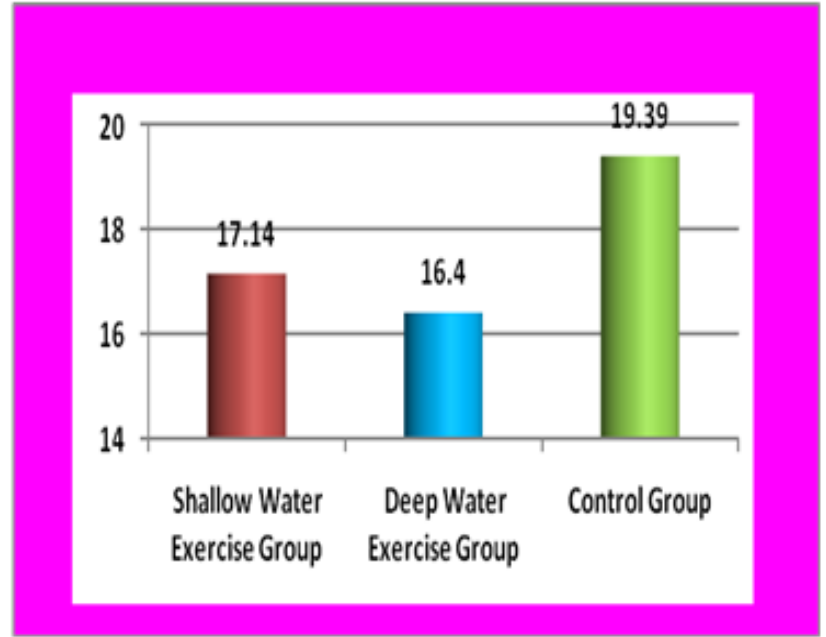

Fig. 2 Bar Diagram on Ordered Adjusted Means of Respiratory Rate

\section{CONCLUSION}

From the analysis of the data, the following conclusions were drawn. Significant differences in achievement were found between shallow water exercise group, shallow water exercise group and Control group in the selected criterion variables such as Flexibility and Respiratory Rate. The Experimental groups namely, shallow water exercise group and deep water exercise group, had significantly improved in Flexibility and significantly decreased in Respiratory Rate. The Deep water exercise group was found to be better than the Shallow water exercise group in increasing Flexibility and decreasing in Respiratory Rate.

\section{REFERENCES}

[1] Kantyka, J., et al., (2015). Effects of aqua aerobics on body Composition, body mass, lipid profile, and blood count in middleaged sedentary women. Human Movement. 16(1), 9-14.

[2] Raffaelli C, Milanese C, Lanza M, \& Zamparo P. (2016) Water-based training enhances both physical capacities and body composition in healthy young adult women. Sport Sci for Health. 12(2), 1-13.

[3] Alberton L, Antunes H, Beilke D, Pinto S, Kanitz C, \& Tartaruga P (2013) Maximal and ventilatory thresholds of oxygen uptake and rating of perceived exertion responses to water aerobic exercises. $J$ Strength Cond Res. 27(7), 1897-1903.

[4] Borreani S, Colado C, Calatayud J, Pablos C, Moya-Nájera D, \& Triplett T (2014) Aquatic resistance training: Acute and chronic effects. Strength \& Cond J. 36(3), 48-61. 